\title{
LVIII. Geological journey to mount Ramazzo in the appenines of Liguria; description of this mountain; discovery of the true variolite in its bed; of lime; of the arragonite; and of martial, magnetic, cupreous, and arsenical pyrites, in the steatitic rock; manufacture of the sulphate of magnesia
}

\section{Faujas St. Fond}

To cite this article: M. Faujas St. Fond (1808) LVIII. Geological journey to mount Ramazzo in the appenines of Liguria; description of this mountain; discovery of the true variolite in its bed; of lime; of the arragonite; and of martial, magnetic, cupreous, and arsenical pyrites, in the steatitic rock; manufacture of the sulphate of magnesia, Philosophical Magazine Series 1 , 30:120, 296-310, DOI: 10.1080/14786440808563823

To link to this article: http://dx.doi.org/10.1080/14786440808563823

Published online: 18 May 2009.

Submit your article to this journal $\sqsubset$

山ll Article views: 3 
junction took place $6^{\mathrm{m}} 35^{\mathrm{s}} \cdot 3$ sooner, or at $21^{\mathrm{h}} 9^{\mathrm{m}} 26^{\mathrm{s}} \cdot 8$ apparent time, when the Sun's true place from the mean equinox by Mayer's tables was $7^{\mathrm{s}} 16^{\circ} 17^{\prime} 13^{\prime \prime} \cdot 3$, or $7^{\mathrm{s}} 16^{\circ}$ $17^{\prime} 8^{\prime \prime} \cdot 5$ if we take into account the correction to be made in the tables which the Greenwich observations make - $5^{\prime \prime}$ nearly. Hence the place of the node is found to be $1^{3} 15^{\circ}$ $58^{\prime} 56^{\prime \prime} \cdot 3$.

LVIII, Genlogical Journey to Mount Ramazzo in the Appenines of Liguria ; Description of this Mountain; Discovery of the true Variolite in its Bed; of Lime; of the Arragonile; and of Martial, Magnetic, Cupreous, and Arsenical Pyrites, in the Steatitic Rock; Manufacture of the Sulphate of Magnesia. By M. Faujas St. Fond*.

$\mathrm{I}_{\mathrm{r}}$ $I_{N} 1780$, Messrs. de Saussure and Pictet visited the mountain Madona della Guardia, elevated 422 toises above the level of the sea, and of which mount Ramazzo forms a part. After having given an excellent lithological description of the first mountain, Saussure thus expresses himself $\uparrow$ : "On ascending and descending the mountain della Guardia, we had a view to the westward of a mountain, from which we were separated by a very deep ravine, and from which we were informed that martial vitriol had been extracted; but I had no knowledge of the substance in which it was found. At the distance from which we saw this mountain, it seemed mixed with slate and ferruginous earths."

It was this mountain, (known by the name of Mount Ramazzo, thus neglected by Saussure, which principally occupied my attention for two reasons; in the first place, because I had been told that trenches were dug at the summit of this mountain, and that a manufacture of sulphate of magnesia had been established there: secondly, because, the steatitic and serpentine rocks of this mountain being united to lime in ccrtain points, I was anxious to visit this curiosity so seldom discovered.

* From Annales du Muséum d'Histoire Nafurelle, tome viii. p. 313.

$\uparrow$ Foyagr de Saussure dans les Alpes, tome iv. p. 145.

M. Maxi- 
M. Maximilian Spinola of Genoa, who is skilled in several branches of natural history, $M$. Viviani a botanist, and my friend M. Marozari of Vicenza, an excellent mineraJogist, were anxious to accompany me. We took our departure at six o'clock in the morning from Genoa: we went in a carriage to Cornigliani, where we visited M. Durazzo's rich collection in natural history: from thence we proceeded to Sestri, where M. Alberto Anseldo conducts a manufactory of sulphate of magnesia with great spirit. This gentleman acted as our guide in the arduous excursion we were about to make: our route lay through narrow by-ways, profound ravines, and we were obliged to climb from rock to rock, which were so flinty and slippery, that they required some experience in alpine travelling to surmount them. We left our carriages at Sestri, and immediately entered the bed of the river Charavagna on foot. We ascended this torrent for about an hour. Its bed is broad, and wholly covered with blocks of serpentine and other round stones; which shows that it is subject to dreadful torrents; but there is scarcely any water in it in dry seasons. The following are the remarks I made on ascending to a lime-kiln, which 1 shall speak of by and by.

\section{Notice upon the Stones in the Torrent of Charavagna.}

1. Various pieces, larger or smaller, of a grayish steatitic rock, of a drier grain than that of the other steatites, of which I shall soon take notice. This rock has fissures or cracks filled with greenish crystallized epidote, similar to that of the alps at Oisan in the ci-devant Dauphiné. I am surprised how this rock escaped the attentive and vigilant eye of Saussure. It is probable, since he has not mentioned it, that the torrent of Charavagna was not then passable, or at least when he visited the mountain della Guardia.

2. Tender serpentine of a blackish green shaded with light green, and shining as if varnished, soft and even unctuous to the touch, radiating into white streaks, with a striated and undulous fracture, having a talcky appearance, and strongly obedient to the magnet.

3. Serpentine, soft, and analogous to that of No. 2, as to 
the constituent parts; but its colour is of a clearer green: its surface is much more glossy than that of the preceding, and its fracture more generally undulated : but what particularly distinguishes this beautiful specimen, which is seven inches long by five broad, is, that it is not only very attractable by the magnet, but endowed with a strong polarity throughout its whole length; and it attracts keenly at one end, while it even repels with the other.

4. Serpentine of a deep green, with some shades of a clearer green, soft to the touch, but harder than the preceding, having ane of its facets striated, and something like asbestos.

3. Another serpentine somewhat hard, of a greenish black, with small spots of a greenish white near to each other, and which seem to have a tendency to the parallelopipedon form, which gives to this variety of serpentine a false aspect of black and white antique porphyry. But what renders the latter remarkahle, is, that it contains in its substance, as well as upon its externall facets, a multitude of very brilliant small silvery scales of metalloidal appearance (diallage), the brilliancy of which is the more lively, as it shines upon a black ground. This serpentine is strongly attracted by the magnet.

6. Semi-hard serpentine, attractable, of a deep greenish black, with some laminæ of metalloidal appearance like silver, and small layers more or less thin, but some of them a line in thickness, of a substance of the unctuous appearance of steatite ; and its colour being olive-green, shining, and of an equal and rich tint, scems to be owing to chrome.

7. Semi-hard serpentine of a blueish-gray, with longitudinal compressed streaks, covered with a slight and transparent couch, or rather with a kind of varnish of a clear azure blue. We also discover in the fractures of this beautiful serpentine, some scales of a metalloid diallage, and of 2 silvery bue; it is attractable by the magnet.

8. Serpentine of a deep greenish-gray, semi-hard, feebly altractable, with small round globules, sometimes oblong, of a compact white or greenish substance, harder and more homogeneous than that of the stone which contains them, 
of a steatitic aspect, and presenting, when we look at it through the microscope, very fine lineaments which unite about the centre of each globule. Here we have a true variolite, which ought not to be confounded with an amygdaloid. The specimen I have described, and which was confounded with the other stones I have mentioned in the bed of the Charavagna, is more remarkable from the globules being distinct, a little projecting and distinct from each other, as in the variolites of Durance, occupying one-third of the size of the speeimen; they are also much nearer together, and seem to touch, and they are confounded afterwards; forming at the extremity of the piece but a single couch where the globules have disappeared, and where the same substance of which they are composed no longer affects the regular form.

This stone fixed my attention, since it gave me reason to expect a variolite analogous to that of Durance, in a place where no person had met with it, or even suspected it to exist.

As the globules, however, of the true variolite belong to a substance very like feldspar and fusible like it, and as I have neither met with compact feldspar, (petro-silex of the Germans,) nor feldspar under other forms; I think the round variolite which I found, was one of those stones transported in great revolutions of the earth, and out of its proper place.

I made these reflections when advancing up the bed of the torrent; but I suddenly discovered a stony mass of a white or greenish hue, weighing more than thirty pounds, which, at first sight, awakened in my mind the idea of feldspar: it may be described as follows :

9. Compact stone, with fine paste, translucid upon the edges, soft to the touch, of a white slightly tinged with asparagus green, having the appearance of jade, breaking into scales rather lamellous than conchoidal, scratching glass strongly, and emitting some sparks when struck with steel; but it is not so hard as the jarle. In the blow-pipe it bubbles up almost as soon as the fire touches it, and melts very soon into a yellowish transparent glass. On breaking this 
stone, we perceived some parts of a lively apple-green, arranged in small elongated lamine, flat and of a silky lustre, owing to the diallage.

I consider this stone as a true compact feldspar, mixed with a little steatitic serpentine, and with iridescence (diallage): it is this mixture which contributes, perhaps, to its great fusibility. I found another piece of it weighing more than twelve pounds.

With the blow-pipe I made a comparative trial of the greenish-white globules of the variolite No. 8, which 1 found in the bed of the torrent, and they bubbled up and melted with the same facility as the stone I have described. Now, as the latter was of a large volume, and did not appear to come from any distance, for its angles were scarcely abraded, I presumed that it should abound in some parts of the neighbouring mountains, in the direction of the torrent which had received these fragments, and that it was perhaps found in a furrow, or mixed into the paste itself of some of the serpentines, which I thought $I$ should find in its proper place. In fact, it was natural to think that the junction of the molecules of feldspar in globules, at the time of the formation of these mountains, might have given rise to variolites analogous to those known by the name of variolites of Durance; and thence I did not lose hopes of finding this kind of stone in the same rock which contributed to its formation.

10. Finally, the bed of the torrent, in proportion as I advanced, presented me with various fragments of a compact calcirequs stone, hard and of a fine paste, susceptible of being polished, with some veins of calcareous spar which traversed it; I saw also some of the same spar adhering to a vein of white quartz.

These calcareous stones found in a considerable number, beside the serpentine, magnesian, and feldsparry stones I have mentioned, left me also some hope of being able to observe the puints of contact of the magnesian with the calcareous rock in a country quite free of wood, and torn up by torrents, presenting great hills and deep ravines. Reflecting in this manner, I advanced a little further, and in a deep 
recess formed by the torrent of the river, I perceived upon an eminence on the right bank of the Charavagna, a rustic habitation, and a large lime-kiln at work.

\section{Of the Calcareous Stone proper for leing converted into Lime, of its Bed beside Serpentines.}

The lime-kiln used for calcining the stone, the singular situation of which 1 shall soon describe, is of so peculiar and unusual a construction, that it is worthy of our attention. In consequence of the extreme scarcity of wood, the saving of fuel has been their principal object: heath and broom only of a large size are used for this purpose; these give a brisk but not a durable fire, and it becomes necessary to endeavour to preserve the heat as much as possible. For this purpose, they have constructed of strong and good masoury, a kind of square tower, stirmounted with a pyramid-formed capital of solid stone, which serves as a kind of roof, and forces the beat to reverberate upon the calcareous stone divided into fragments and intended to be calcined. A simple straight aperture towards the top of the vault serves for letting out the smoke, and the humidity which exhales from the calcareous stone and combustible; and it establishes a current of air necessary for keeping up the fire, which being concentrated in a great measure by the obstacles opposed to its wasting, acquires 2 greater and steadier intensity. If, in some peculiar circumstances, they require a greater current of air, it may be easily obtained by opening a small door placed in one of the faces of the pyramidal wall, which serves as a roof to the furnace. The lime-stone is introduced by a door made behind the furnace, and it is withdrawn by the same aperture when it is calcined: the combustibles are placed below npon a grating.

The quarry of lime-stone is not far off, and is to be seen in the kind of ravine which serves for the bed of the torrent. As my intention was to follow it in several points, so as to become well acquainted with its situation, I continued to ascend the torrent of Charavagna, by a route which becomes more rapid as we advance. The soil was every where loaded 
with serpentines of various kinds similar to those I have. mentioned : but there were also found considerable blocks of a mass composed of fragments of the serpentines above described, and of the same lime I have mentioned, and similar in every respect to that of which the lime is made: this mass is strnngly united by a calcareous sparry cement.

A second kind of mass, also arranged in large blocks, is to be found in the neighbourhood of the first : both have been detached from the neighbouring mountains, and do not seem to bave been brought from any distance : the one in question is composed only of larger or smaller fragments of different kinds of serpentine, which have entered into the composition of the neighbouring mountains; but we find no lime in it as in the first mass, and the cement which has united these serpentines has lime in it, being entirely steatitic. We soon tnet with these two varieties of masses again upon the edges of one of the ravines of the torrent, on the one edge beside some serpentines, and on the other adhering to lime. It seemed at first sight as if these masses served as intermedia, and were passing from one genus to another : but in examining them again, and reflecting that they must have been formed at the expense of the calcareous and steatitic rock, both of which must have had at this period the same consistency and the same hardness as at present, we could only attribute this formation to an accidental revolution, long subsequent without doubt to events of another order, which have given birth to these mountains of serpentines, and to the calcareous beds adhering to them, and which have furnished the materials for these two masses. But let us now cast a glance upon the lime in its bed, and see if it be cotemporary with the serpentine rock, or if it be subsequent.

At a certain distance from the lime-kilu, and not far from the hamlet of Serra, placed in an amphitheatre near the precipice which hangs over the torrent of Charavagna, we may observe in a very distinct manner a part of the calcareous layers in their points of contact with the magnesian rock. I give the preference to this spot over that which is nearer the lime-kiln, because we see more distinctly 
the junction of both substances; and the doubts we might raise as to the lime-stone placed against it secondarily, and afterwards against the serpentine rock, disappear entirely upon examining the facts I have mentioned.

In short, when the torrent in its various overflowings, and when after storms its waters are precipitated from precipice to precipice with a violence and impetuosity carrying every thing before it, and laying bare the calcareous and serpentine beds, so as to present the whole at full view; we then remark the gray, hard, and compact lime-stone, which is modified into white calcareous spar, and forms large strings or lineaments, which are joined and interlaced with very small layers or lineaments of steatitic serpentine. These lineaments sometimes increase, and are developed longitudinally, and like stripes of a gray or greenish colour around longitudinal or circular laminx of calcareous spar of a white colour. In other parts adjacent, the two substances form a kind of net-work. In a word, we think we can perceive in the union and in the play of these two substances, so different in their nature, the results of the movement of the fluid which held both in solution at one and the same time; and we only know the waters of the sea, and their long continuance upon these regions, at very remote periods, as having acted upon masses which constitute chains of mountains.

Every thing, therefore, inclines us to think, that in this case the lime-stone has been attached, or rather joined, to the magnesian rock, not by an after process, but in one and the same operation, when great accumulations of dissolved calcareous matters being in the neighbourhood of substances which have given birth to the serpentine rock, their molecules floated in the same fluid, which gave rise to points of meeting, centact, union, and mixture, similar to those we observe here. Nothing proves more completely that this mixture is made simultaneously than the chemical state of these two substances; for the purest of the lippe-stone contains 6,7 , and even 8 per cent. of magnesian earth, while the serpentine rock has as much lime-stone in its mass. 
Saussure had remarked upon the mountain della Guardia, an alternation of calcareous and serpentine layers; which is perfectly analogous to what $I$ have here described. But as such an operation could not be performed at a single jet, we cannot refrain from remarking here also that nature never takes into her account the operations of time.

\section{Of the true Variolite (Variolites viridis verus) in the same Rock in which it has been produced.}

As our object was to visit the quarrying of the materials used in the manufacture of sulphate of magnesia upon the highest part of Mount Ramazzo, M. Alberto Ansaldo, who guided us, informed us that we must leave the bed of the Charavagna, pass to the hamlet of Serra, and ascend over shelving precipices into a direction opposite to that of the torrent. The road, or rather the pass, was strait, rapid, and slippery; we were surrounded on all sides by serpentine rocks more or less green; some were hard, others soft : the grain of them also varied; in some places it was dry, and in others greasy and unctuous : enormous masses, placed upon still huger masses, spread spontaneously, some into irregular leaves more or less turned, and others into striated pieces imitating asbestos : the diallage was distinct in some fractures, and exhibited a silvery lustre; in others this was not to be seeu; and in this case the heart of the stone, being of a deep blackish green, presented shades of a clearer green.

We had ascended at least six hundred feet in height from the hamlet of Serra; when being at this height, not far from a small stream of water which runs through the pass, and might serve as a point for reconnoitring, I perceived a detached piece of serpentine, the surface of which was covered with small globules of a whitish green, a little projecting, and harder than the paste of the stone. I saw with pleasure that it was a variolite not rolled nor trans. ported from its place, but detached spontaneously by the effect of moisture, or the alternation of heat and cold, from an enormous mass of serpentine which was contiguous. 
This fine specimen is five inches long by three broad; one of its facets presents the whole characters of a fine green variolite, with small grains projecting a little, and of a green much clearer than the heart of the stone, while the opposite part is a true serpentine of a dark green, without globules or variolitic spots. We could not doubt, after looking at this specimen, that the substance which was joined in globules in order to form this variolite, was the result of an assemblage of a certain quantity of feldsparry subsiance, the elements of which had been mixed in the serpentine rock at the time of its formation. This kind of separation may be considered as the result of a globulous imperfect crystallization, determined by the attractive force of the fieldsparry molecules, which bad more affinity for each other than for the magnesian earth; and if these variolitic globules are only superficial as it were, (for the bed in which we remark them is little more than three lines thick, it is because the substance of the feldspar was not abundant. In short, the identity of the globulous substance is absolutely the same with that which I found, separated and in voluminous pieces, in the bed of the Charavagna, and which I have mentioned in No. IX of the description of stones found in this torrent. In fact, having attacked with the blowpipe some globu es of the variolite in question, they swelled upon the first attack of the fire, emitted some air bubbles, and formed a yellowish transparent glass, like the feldsparry stone above mentioned.

A variolite equally well characterized, in the neighbourhond of the rock of which it had once formed a part, gave me good hopes of meeting with some more of them. These hopes were soon realised; for after we had ascended 300 feet higher, we found beneath our feet several flat pieces, but angular, and of hard serpentine of a lighter or darker green filled with variolitic globules, the grains of which were much, thicker, and penetrated into the whole mass of the serpentine. I gathered several fise specimens, some of which are six or eight inches long by an inch in thickness, and of so decided a character that we can easily distinguish with Vol. 30. No. 120. Mlay 1808. 
the microscope the commencement of the kind of radiated crystallization which is peculiar to each globule.

The higher we ascended, the more of these specimens did we find at the foot of the rocks of serpentine. I observed with interest the general tendency these rocks naturally have to divide into splinters, or into large ftat and scaly fragments; (this I attributed to a peculiar alteration of the iron so abundant in this kind of stone;) when I suddenly perceived upon the right of the pass, a mass of serpentine in its bed more than eighteen feet high, with a base of 40 feet broal, and which seemed as it were isolated, either by natural and spontaneous decomposition of the most tender parts of the rock, or by some other cause. I perceived upon this large mass some parts much greener than others, penetrating deeply into the heart of this enormous block, which was of a very dull blackish green.

I approached very close, and I ascertained that most of the spots were produced by parts abounding in true variolite of a grass green colour, and white spots or grains, shaded from an extremely clear green. All these parts formed in variolites seemed extremtly hard: I had soor some proofs of this, when I struck them with a hammer, and it was with great difficulty I obtained some good specinens.

Several of these pieces had a multitude of globules analogous and similar in every respect to the variolite of $\mathrm{Du}$ rance : sometimes, however, the variolitic spots only entered to the depth of an inch and a half into the stone, and the rest seemed to be nothing else than a pure serpentinous rock; at other places the variolite entered deeper into the mass: in sone places the granulous surface was not much larger than the palm of the hand; in others it was double this size: in short, by continuing to observe more variolites in other blocks, I was convinced that this singular stone is not in a vein in the masses of serpentines, but that it exists indifferently, sometimes in one place and sometimes in another, without order or regularity. It is the same with the arrangement of the globules: we see them huddled together upon some pieces, and as it were arranged 
in an equal and distinct manner, while they are thinly scattered upon others, or sometimes so close tngether that they are confounded, and form merely a large whitish spot.

I shall finish these details by observing, that I possess among my numerous specimens a remarkable piece, which will demonstrate to those acquainted with the composition of rocks, that the variolite of Mount Ramazzo took its rise in a true serpentinous rock. I shall now describe this rare and curious specimen in few words.

Its colour is the same with that of the other serpentines I have mentioned; but the rock from which 1 detached it with the hammer was very hard, its texture very close; but striated at the same time in a scaly manner; and its scales frequently interposed between the streaks, and intersecting them transversely, render this rock difficult to break: it is torn in some measure rather than broken, and requires heavy blows witli the hammer. In this way I procured this fine specimen with a fracture a little undulous, but pure and clean, and which admits of our seeing upon the two large faces of the stone its texture, as well as upon the rock itself. We sce perfectly upon a part which forms almost the half of the piece, and not only. upon the faces but throughout its whole thickness, a multitude of variolitic globules of almost equal size, of a clear green, issuing every where from the streaks and scaly parts of the stone, as if they were sown in it: these globules become smaller afterwards in proportion as they approach that part of the specimen which has none of them; and this last part is then nothing bat pure serpentine inixed with some irregular and thin lineaments of a white colour, not belonging to the variolite, and some of them slightly efferresce with the nitrid acid.

from the above facts we see tinat the true variolite exists in Mount Ramazzo, and that it is cotemporary with the serpentines in which we find it at the height of more than 1500 ficet above the level of the sea. It is tu be presumed we shall find it at a greater tevation, and perhaps in still greater abundance, in other parts of the Ligurian Appenines. 


\section{Of the Mine of Magnesia upon the highest Part of Mount Ramazzo.}

The route becomes more and more diffcult as we approach the rugged summit, where the quarries and establishment of M. Alberto Ansaldo are situated, nor do we lose sight of serpentine rocks the whole way: these are more or less compact, lamellous, streaked, glossy, unctuous, or dry and friable. We pass several ravines, and mount from precipice to precipice, until we come to about 1800 feet above the level of the sea, being the summit of Mount Ramazzo, where we find a small flat piece of ground, upon which are built some penthouses for preparing the mineral, and apparatus for stamping, roasting, leying, \&c.;-in a word, for extracting the sulphate of magnesia in a simple and interesting manner.

This operation consists in carefully collecting a very pyritous steatite, which is found rather in heaps and large fragments than in regular seams: they afterwards roast it, after reducing it to pieces, in order to evaporate a little of the arsenic which is combined with it. It is in this operation of roasting that the sulphur which is combined with the iron is disposed to quit its base, and attaches itself to the magnesian earth of the serpentine, in order to form the sulphate of magnesia. They pound this roasted pyrites in a rough manner; it is then arranged in large heaps, which they water slightly: the combination with the magnesian earth is then finished by a slow fermentation which the matter undergoes : these earths are afterwards leyed, and a very abundant sulphate of magnesia is obtained, which is purified and refined in another establishment belonging to $\mathrm{M}$. Alberto Ansaldo, at Sestri.

After having examined the first preparation of the ferruginous and arsenical pyrites of Mount Ramazzo, we entered the galleries of the mine, which are close to the penthouses: they are large, but the working of them is not regulated : they follow the pyrites and the pyritous steatite wherever they meet it, sometimes in a straight line and sometimes laterally, just as it presents itself. The excavations are made 
in an irregular manner, and without any precautions for the safety of the workmen: the pickaxe, however, alone is used. The explosion by gunpowder would certainly bring down the roofs of the quarries, which are no where supported by props or bulwarks. The various specimens I collected here were :

1st. A greenish steatite, the surface of which, as well as its interior texture, is penetrated with a kind of pyritous varnish of a bronze colour, but so light and so efflorescent (if I may use the expression) that it seems as if the heart of the steatite, which is black, was shown through this kind of varnish. Tris pyritous steatite is very heavy; it blackens paper, and moves the magnetic needle strongly. It contains a small proportion of copper, but scarcely perceptible.

2d. The same steatite, still richer in pyrites, with the slight yellowish or bronze varnish I have mentioned, which seems to gild the black serpentine rock, is soft to the touch, blackening the fingers, and forcibly obedient to the magnet. We find in the same rock arsenical magnetic pyrites, very heavy, and with a metallic fracture of a grayish white.

$3 \mathrm{~d}$. This is a rare and superb specimen, being five inches nine lines long by four inches broad: the base of it is a serpentine of a deep black, a little glossy, blackening paper, without a pyritous appearance; but very heavy, and strongly attractable by the magnet, remarkable from needles of transparent white arragonite, one crystal of which is two inches three lines long and four lines in diameter, of a hexagonal figure, but always without a pyramid. Other crystals of a still greater diameter are to be seen, sonetimes in kinds of cavities in the specimen, sometimes in the mass itself of the pyritous serpentine, and scem to have been formed simultaneously with the pyritous and nagnesian elements of which this rock is composed.

4th. We find a few yards from the quarries, and a little lower down, some old excavations, but not so deep : here there is a striated and silky-like pyrites, with heautiful green efflorescences of carbonated cupper. This steatite is $\mathrm{U} 3$ soft 
soft to the touch, and has yellow ochrey spots in it, apparently proceeding from grains of altered cupreous and ferruginous pyrites. M. Ansaldo informed me, that this pyrites was formerly wrought for the sake of its sulphate of copper, but abandoned on account of its poverty.

LIX. Essay upon Machines in General. By M. Cannor, Menber of the French Institute, $\mathscr{E}^{\circ} \mathrm{c} . \mathrm{S}^{2} \mathrm{C}$.

[Continued from p. 221.]

\section{Problem.}

XX. THE virtual movcment leing known of any given system of hard lodies, (i. e. that which it would assume if each of the bodies were free, ) to find the real movement which it should have the following instant.

Solution. Let us denominate each molecule of the

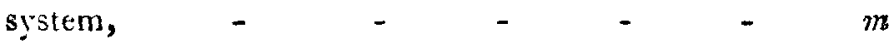

Its virtual given velocity, - $\quad-\quad-W$

Its real velocity sought, - $\quad$ - $\quad$ - V

The relocity it loses, in such a manner that $W$ is the result of $\mathrm{V}$ and of this velocity, - $\quad$ - U

Let us now imagine that we make the system assume an arbitrary geometrical movement, and let the velocity which $m$ will then have be - $\quad$ - $\quad-\quad u$

The angle formed by the directions of $W$ and $V, \quad X$

The angle formed by the directions of $W$ and $U, \quad Y$

The angle formed by the directions of $V$ and $U, \quad Z$

The angle formed by the directions of $\mathrm{W}$ and $u, \quad x$

The angle formed by the directions of $\mathrm{V}$ and $u, \quad y$

The angle formed by the directions of $\mathrm{U}$ and $u, \quad x$

This being done, we shall have the equation $s m u U$ cosine $z=0(F)$; by means of which we shall find in all cases the state of the system, by attributing successively to the indeterminates $u$ different relations and arbitrary directions.

Definitions.

XXI. Let us imagine a system of bodies in movement in 